$30-5 / 9$

XI International Congress of $\mathrm{Cli}$. nical Chemistry

$7^{\text {th }}$ Congress CHISA

Setembro

\begin{tabular}{|c|c|c|}
\hline $6-11$ & Mainz & $\begin{array}{l}8^{\text {th }} \text { International Congress on me- } \\
\text { tallic corrosion }-7 \text { th Congress of } \\
\text { the European Federation of Cor- } \\
\text { rosion }\end{array}$ \\
\hline $7-10$ & $\begin{array}{l}\text { University } \\
\text { College of } \\
\text { North } \\
\text { Wales, } \\
\text { Bangor } \\
\text { (G. B.) }\end{array}$ & $\begin{array}{l}\text { Structure and Reactivity of Car- } \\
\text { bocations }\end{array}$ \\
\hline
\end{tabular}

14-16

Outubro

$\begin{array}{ll}\text { 4. } 9 & \\ \text { 4- } 9 & \text { Montreal } \\ & \text { (Canadá) }\end{array}$

of Nottingham (G. B.) (Hungria)
General Discussion: Selectivity in Heterogeneous Catalysis

Budapeste

VIIIth Symposium Industrial Christallization

$2^{\text {nd }}$ World Congress on Chemical Engineering and World Chemical Exposition

\title{
CONFERÊNCIA INTERNACIONAL SOBRE EDUCAÇÃO EM QUÍMICA
}

Dublin, 27.31 de Agosto de 79

Tema: 0 ensino da Quimica - Intervenção entre os níveis secundário e terciário
A Dublin, cidade dos congressos, deslocaram- se cerca de 400 professores dos ensinos secundário e terciário provenientes de 57 paises para parti. ciparem numa conferência internacional cujo tema foi 'O ensino da Química -- intervenção entre os niveis secundário e terciário'.

Em cada dia da conferência houve um assunto principal apresentado sob dois pontos de vista, o do ensino secundário e o do ensino terciário. Seguidamente, em grupos de cerca de 20 participantes, discutia-se o assunto do dia, durante o resto da manhã, e as conclusões destas discussões foram apresentadas no fim do dia em sessão plenária. Além disso, os assuntos focados em algumas das conferências plenárias foram discutidos numa base regional (Africa, Ásia, Europa de expressão francesa, resto da Europa, continente norte-americano, continente sul-americano).

A conferência foi ainda preenchida com três sessões de posters em 3 tardes, nas quais foram expostos cerca de 90 posters.

\section{1 - Que quimica precisam os quimicos e os cidadãos (em geral)?}

O Dr. Stig Anderson, director da Katedraeskola em Lund, na Suécia, considera que actualmente uma pessoa culta deve ter um conhecimento de ciências, incluindo conhecimentos de Quimica. Apesar disto, nota-se nos últimos anos, em muitos paises, que o interesse dos alunos por estudos de Quimica diminuiu.

O conferencista considera essencial, para que o ensino da quimica seja estimulante para os alunos e thes proporcione conhecimentos do assunto o seguinte: 
a) o curriculo deve estar orientado para as ex. periências dos próprios alunos e para as aplicações da quimica na vida diária e na tecnologia;

b) o curriculo deve ter uma construção lógica;

c) as experiências feitas pelos alunos e as demonstrações feitas pelos professores não devem ser apenas experiências com tubos de ensaio;

d) deve referir-se o desenvolvimento continuo das ciências em termos de novas teorias (modelos)

O conferencista considera que é desejável que no curriculo de todos os alunos se inclua quimica pois qualquer cidadão (nomeadamente os politicos), terá que tomar decisōes no campo da energia ou do ambiente, e jornalistas e repórteres informarão o público acerca destes assuntos.

O Professor David Brown, de University College, em Dublin, sugeriu que apesar das actuais pressões sociais e políticas deve manter-se como peça essencial de um curso universitário o desenvolvimento lógico e a inter-relação entre a teoria e a experiência; contudo, estes principios devem aplicar-se a um certo número de áreas (energia, ambiente, entre outras), em que se evidencie não só a inter-relação anteriormente referida mas também a relação entre as disciplinas académicas e os desenvolvimentos industriais que provaram ter importância social e económica. Este ponto de vista tem estado a ser aplicado no ensino secundário por um grupo de trabalho do Instituto de Quimica da Irlanda que está a planear uma estrutura e um curso em que se proporcione não só a compreensão dos conhecimentos de quimica. mas também das aplicações da química.

Nos grupos de trabalho discutiram-se duas questôes: Que quimica se deve ensinar e que se deve fazer no futuro para os alunos que pensam prosseguir estudos de quimica, e para os outros alunos. A sessão plenária foi presidida pela Professora Marjorie Gardner, da Universidade de Maryland em Washington, USA.

\section{2 - Que equilibrio deve existir entre facto e teoria no curriculo?}

O Director de Riccarton Nigh Sechool, na Nova Zelândia, Terry Hitchings, referiu-se aos programas existentes no ensino secundário que são determinados pelas universidades e limitados pelos exames. Como estes programas têm muitos principios abstractos, a química descritiva tem sido ensinada de um modo inadequado. O dilema facto-teoria tem sido delimitada pela experiência.

Do ponto de vista dos alunos os factos podem constituir um estimulo; estes devem ser examinados à luz de teorias após o que se devem procurar aplicaçōes. Mas a inclusão de factos que ilustram a teoria de um modo perfeito faz com que os alunos fiquem demasiados confiantes.

Para se encontrar um equilibrio entre facto e teoria deve considerar-se a quem se destina o curriculo, procurando-se identificar os problemas dos alunos. O currículo deve ser orientado primeiro para a observação dos factos e depois para a exposição da teoria (explicação) tendo em atenção que observações simples devem estar ligadas a explicaçōes simples

O Professor J. Padilla, da Universidade Autónoma do México, disse que aceita como necessário que o ensino da química seja baseado em trabalho laboratorial. No México o ensino prático da quimica está limitado por factores, como a pressão causada pelo aumento de população, e a falta de materiais e elementos humanos com qualificações adequadas. A falta de metodologia que permita determinar e justificar o conteúdo experimental de um curso faz com se copie o que se produz no estrangeiro. Na Escola de Química da Universidade do México procuraram-se outras alternativas tendo-se criado um curso básico de laboratório, com um resultado positivo, após alguns anos de esforço continuo. Embora nem tudo o que se planeou tenha resultado a criação deste curso mostrou que não há soluções simples mas apenas escolhas inteligentes.

Nos grupos de trabalho discutiram-se duas questōes:

- como estabelecer uma melhor interaccão facto-teoria em cursos de quimica?

- até que ponto devem os cursos de química estar relacionados com processos (capacidades e atitudes)?

A sessão plenária foi presidida por Valerie Hewett, da Escola de Educaçăo da Universidade de West Indies na Jamaica.

3 - No $3 .^{\circ}$ dia de trabalhos realizaram-se duas sessões paralelas

\section{Equilibrio químico e Energética}

O Professor G. Teterin, da Universidade de Odessa, URRS, mencionou a existência de alguns problemas que surgem aos alunos no estudo do equilibrio químico. Por exemplo, no estudo do principio de Le Châtelier os alunos visualizam a existência de dois compartimentos e pensam no que acontece em cada compartimento. No estudo de catalizadores os alunos pensam que estes conduzem a reacção numa determinada direccão. Em face disto o professor necessita ter uma lista de problemas que os alunos manifestam.

O conferencista considera que nos novos curricula deve introduzir-se termodinâmica, pois ensinar quimica com elementos de termodinâmica é ensinar química moderna.

A Doutora Nida Sapianchai, Directora do Instituto para a Promoção do Ensino da Ciência e da Tecnologia (IPECT), em Bangkok, Tailândia, iniciou a conferência pondo as questões: porquë ensinar quimica?, que química ensinar?, por que ordem se deve ensinar quimica?. Indicou objectivos para o ensino da ciência, critério para a selecção de conteúdos e características do curri- 
culo de quimica ensinado no IPECT. Seguidamente discutiu os problemas do ensino da energética no curso secundário pois, ao misturar substâncias, verifica-se que:

- umas vezes ocorre reacção, outras não;

- umas vezes há libertação de calor, outras vezes há absorção de calor:

- algumas reacções dão-se por completo, outras não;

- umas reacções são rápidas, outras são lentas.

Considera a conferencista que no ensino secundário não se deve falar em entalpia de reacção, embora se possa usar a designação $\Delta \mathrm{H}$. Quanto à Lei de Hess pode ser apresentada de um ponto de vista matemático e, se possivel, confirmada no laboratório.

Concluiu a conferência referindo-se à necessidade de investigação na área do ensino da energética e do equilibrio quimico.

Nos grupos de trabalho discutiu-se a questão: na interface entre a educação no secundário e no terciário ao ensinar-se equilibrio deve introduzir-se as noções de entalpia, energia livre, entropia? Presidiu à sessão plenária o Professor D. Vitoric. da Universidade de Belgrado na Jugoslávia.

\section{Estrutura e Ligação quimica}

Joseph Chester, de Colaiste Choilim, na Irlanda, sugeriu que as criticas ao ensino dos conceitos de ligação química no ensino secundário são devidas mais às estratégias de ensino adoptadas e não tanto a dificuldades inerentes ao assunto.

O Professor Henry Bent, da Universidade de North Carolina, Raleigh, USA, baseou a sua conferência em dois pontos: ligações covalentes que o átomo de carbono forma e algumas regras de quimica estrutural.

A sessão plenária foi presidida pelo Doutor $\mathrm{N}$. Fitzpartick, de University College, Duolin.

\section{4- Como educar professores de quimica}

O Doutor Sam Bajah do Instituto de Educação da Universidade de Ibadam, na Nigéria, referiu-se à preparação de professores de quimica para o nivel secundário que deixou de estar orientada apenas para cursos convencionais de quimica para estar orientada para as relações preponderantes da quimica com a sociedade e com o meio. A procura da química pura como uma base académica para várias profissões foi suplantada pela procura da química para todos - quimica que dê a oportunidade de desenvolvimento do homem na sua totalidade. A química é considerada como um veículo para trazer paz e estabilidade para a humanidade. Em resultado disto, a educação de professores de quimica tem que ter uma visão mais alargada.
Os professores de quimica devem ter uma boa preparação académica e devem melhorá-la pois não ensinam apenas o que sabem. A preparação de professores não deve ser feita para classes ideais, pequenas, mas os professores devem ser preparados para ensinar quimica a classes grandes, entusiásticas, já que em muitos paises em desenvolvimento a frequência escolar tende a aumentar.

O Professor Maurice Gommel, da Universidade de Poitiers, França, seleccionou como objectivo principal da sua conferência: a quimica pode ser a matemática de amanhã. O conferencista considera que se deve ensinar quimica realçando as suas dimensões culturais, e deve dar-se aos alunos a possibilidade de descobrirem as relaçōes entre os vários aspectos da realidade. Deste modo a quimica pode vir a ser a matemática de amanhã.

As questões postas aos grupos de trabalho foram em maior número que nas sessões anteriores:

1 - Como se deve processar a preparação dos professores de quimica, atendendo ao conteúdo académico, capacidades pedagógicas e encorajamento de uma atitude positiva?

2 - Quais devem ser as finalidades e funções de estágio e de reciclagens?

3 - Como preparamos os professores para se adaptarem ao que existe e serem inovadores?

4 - Atendendo a que não há muitos problemas devidos ao conteúdo, finalidades e necessidades dos diversos paises, qual é o programa comum da preparação de professores de quimica?

No entanto, não foi possivel fazer-se a discussão de mais que uma ou duas das questões formuladas. Algumas das conclusões foram:

- os professores devem ser pessoas abertas que saibam ouvir os alunos e identificar problemas de aprendizagem;

- os professores universitários devem ter, pelo menos, a mesma preparação pedagógica que os professores do ensino secundário;

- a preparação pedagógica deve vir depois da preparação académica;

- os professores devem utilizar vários métodos de ensino;

- o sucesso do ensino é proporcional ao grau de envolvimento do aluno;

- os professores devem trabalhar no equilibrio Ensino $\longleftrightarrow$ Investigação.

A sessão foi presidida pelo Doutor Ram Kulkarni, de Shroff Research Institute em Bombaim. 


\section{Sessões de posters}

Nas sessões de posters os temas e métodos utilizados foram muito variados, desde a simples apresentação de 'papers' expostos no placard, até aos que utilizaram videotape. Os participantes aproveitaram a oportunidade de falar com os autores dos posters apresentados para poderem esclarecer algum ponto do assunto que thes interessaram.

\section{Sessão de encerramento}

Ao fim de quatro dias de trabalho a conferência terminou. Antes, porém, foi anunciada a data e - local da próxima conferência internacional: Universidade de Maryland, em Washington, USA, em Agosto de 1981:

MARIANA P. PEREIRA (Liceu de Queluz)
(*) Atendendo a que há muitos problemas devidos ao conteúdo, finalidades e necessidades dos diversos paises, qual é o programa comum da preparação de professores de quimica?

\section{ACTIVIDADES DA S.P.Q.}

\section{Reunião Internacional de Presidentes de} Sociedades de Quimica
Realizou-se em Washington, entre 15 e 17 de

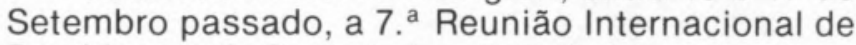
Presidentes de Sociedades de Química.

Em 1967 o Doutor C. Overberger, então presidente da American Chemical Society (ACS) convidou os presidentes de Sociedades de Química de outros paises para discutirem, em Washington, assuntos de interesse comum das Sociedades. Nove paises se fizeram representar no que constituiu a primeira dessas reuniões, pois foi tal o seu êxito que foi decidido prosseguir com reuniões desse tipo de dois em dois anos. As reuniões que se seguiram foram todas na Europa Ocidental, sendo a última de novo em Washington, e a próxima prevista para realizar-se na Yugoslávia.

De ano para ano se tem vindo a notar um maior número de adesões de novos países. Na reunião que se realizou em Setembro passado, e em que a SPQ se fez representar pela primeira vez, participaram representantes de Sociedades de Quimica de 36 paises espalhados por todos os Continentes.

A reunião teve lugar na excelente sede da ACS e concentrou as suas actividades em dois dias e meio, com uma agenda de trabalhos extremamente compacta mas que, dada a eficiência da organização, foi possivel cumprir integralmente.

Os temas tratados foram muitos e variados sendo apresentados quer individualmente quer sob a forma de mesas-redondas. Uma caracteristica de todas as sessões foi o tempo dedicado à discussão ser sempre ampla, permitindo a aprecia- 